\title{
INTELECTUAIS, MEMÓRIA E POLÍTICA ${ }^{1}$
}

Dermeval Saviani ${ }^{2}$

\section{RESUMO}

Este artigo aborda a relação entre intelectuais, memória e política começando pelo esclarecimento do conceito de intelectual em sentido amplo e, traçando um esboço histórico da emergência da função intelectual, esclarece o sentido estrito do conceito de intelectual. A partir daí caracteriza o significado político e a condição histórico-social dos intelectuais, mostra a relação entre intelectuais e memória coletiva encaminhando, por fim, a questão da criação de intelectuais orgânicos de um novo tipo.

Palavras-chave: Intelectuais orgânicos; Intelectuais tradicionais; Intelectuais e história; Intelectuais e memória; Intelectuais e política.

\section{INTELLECTUALS, MEMORY AND POLITICS}

\begin{abstract}
This article deals with the relationship between intellectuals, memory and politics, starting with the clarification of the concept of intellectual in a broad sense and, by drawing a historical draft of the appearance of the intellectual function, it clarifies the strict meaning of the concept of intellectual. From there, it characterizes the political meaning and the historical-social conditions of the intellectuals. It shows the relationship between intellectuals and collective memory and, finally, it moves to the question of the creation of organic intellectuals of a new kind.
\end{abstract}

Key words: Organic intellectuals; Traditional intellectuals; Intellectuals and history; Intellectuals and memory; Intellectuals and politics.

\section{INTELECTUALES, MEMORIA Y POLÍTICA}

\section{RESUMEN}

Este artículo cubre la relación entre los intelectuales, la memoria y la política empezando por la aclaración del concepto de intelectual en un sentido amplio y estableciendo un boceto histórico de la aparición de la función intelectual, aclara el sentido estricto del concepto de intelectual. A partir de ahí caracteriza el significado político y la condición histórico-social de los intelectuales, y muestra la relación entre los intelectuales y la memoria colectiva, encaminando, finalmente, la cuestión de la creación de intelectuales orgánicos de un tipo nuevo.

Palabras-clave: Intelectuales orgánicos; Intelectuales tradicionales; Intelectuales e historia; Intelectuales y memoria; Intelectuales y política. 
O significado do conceito de "intelectual" deriva originariamente da particularidade da espécie humana que, não tendo sua existência garantida pela natureza, é obrigada a agir sobre ela e transformá-la. Nesse processo o ser humano produz sua própria existência, fenômeno esse que se expressa pelo conceito de "trabalho". Esse conceito foi explicado de forma clara por Marx ao tratar do trabalho em geral, considerando-o "à parte de qualquer estrutura social determinada":

Antes de tudo, o trabalho é um processo de que participam o homem e a natureza, processo em que o ser humano com sua própria ação, impulsiona, regula e controla seu intercâmbio material com a natureza. Defronta-se com a natureza como uma de suas forças. Põe em movimento as forças naturais de seu corpo, braços e pernas, cabeça e mãos, a fim de apropriar-se dos recursos da natureza, imprimindo-lhes forma útil à vida humana. Atuando assim sobre a natureza externa e modificando-a, ao mesmo tempo modifica sua própria natureza. Desenvolve as potencialidades nela adormecidas e submete ao seu domínio o jogo das forças naturais. Não se trata aqui das formas instintivas, animais, de trabalho (MARX, 1968, p. 202).

E, após assinalar a diferença histórica entre o trabalhador sob a forma capitalista e o homem primitivo com sua visão ainda instintiva, Marx reafirma:

Pressupomos o trabalho sob forma exclusivamente humana. Uma aranha executa operações semelhantes às do tecelão, e a abelha supera mais de um arquiteto ao construir sua colméia. Mas o que distingue o pior arquiteto da melhor abelha é que ele figura na mente sua construção antes de transformá-la em realidade. No fim do processo do trabalho aparece um resultado que já existia antes idealmente na imaginação do trabalhador. Ele não transforma apenas o material sobre o qual opera; ele imprime ao material o projeto que tinha conscientemente em mira, o qual constitui a lei determinante do seu modo de operar e ao qual tem de subordinar sua vontade (Idem, ibidem).

Ora, esse ato de antecipar na mente o que será realizado, de imprimir à matéria o projeto de ação conscientemente formulado põe em evidência que o trabalho, isto é, a atividade propriamente humana, articula corpo e mente, a ação prática com a teórica, o ato manual com sua expressão ideal. Eis aí como se manifesta o conceito de intelectual. Por isso Gramsci pôde dizer que "todos os homens são intelectuais", acrescentando, porém: "mas nem todos os homens desempenham na sociedade a função de intelectuais", o que é aclarado com a seguinte nota de rodapé: "Do mesmo modo, pelo fato de que alguém possa em determinado momento fritar dois ovos ou costurar um buraco do paletó, não quer dizer que todo mundo seja cozinheiro ou alfaiate" (GRAMSCI, 1968, p. 7).

Essa unidade da atividade especificamente humana que nos permite considerar que não existe trabalho puramente manual, pois "mesmo no mais mecânico e degradado existe um mínimo de qualificação técnica, isto é, um mínimo de atividade intelectual criadora" (idem, ibidem), não significa identidade de seus elementos constitutivos, mas diferenciações no interior de um mesmo todo. Por isso, como veremos a seguir, a função intelectual muito cedo começou a se manifestar como distinta da função manual. 


\section{A emergência da função intelectual: esboço histórico}

Já nas origens da humanidade, na etapa correspondente ao comunismo primitivo, é possível observar o referido fenômeno da conversão do aspecto intelectual em uma função social específica a ser exercida por membros diferenciados no seio de cada forma particular de sociedade. Assim, nas sociedades primitivas, que podem ser exemplificadas pelas tribos indígenas que viviam em nosso território quando aqui chegaram os portugueses no alvorecer do século XVI, "havia clara igualdade de participação na vida da sociedade por parte de todos os seus membros, não havendo outras formas de diferenciação senão aquela decorrente da divisão sexual do trabalho" (SAVIANI, 2010a, p.37).

Nesse contexto a questão intelectual representada pelos conhecimentos e técnicas socialmente disponíveis era acessível a todos. Com efeito, tais conhecimentos e técnicas eram assimilados nas relações sociais entre todos os membros da tribo e não apenas entre os adultos e as crianças e jovens, o que fazia com que cada membro era, ao mesmo tempo, discípulo e mestre em relação aos demais. Entretanto, ocupavam posição de destaque os que tinham atingido a idade da experiência, isto é, os maiores de 40 anos, que eram respeitados e cujos exemplos e preleções serviam de orientação a todos os membros da tribo. Por isso a eles cabia ocupar os "postos-chave na vida social (os chefes de grupos locais), na vida militar (líderes guerreiros) e na vida religiosa ou esfera sagrada (pajés e pajé-açu). Suas exortações cumpriam o papel de atualizar a memória coletiva, preservando e avivando as tradições tribais" (idem, p. 38).

Com o advento da sociedade de classes propiciada pelo aparecimento da propriedade privada, manifesta-se claramente a divisão entre trabalho manual e intelectual. Assim, nas sociedades antigas ou escravistas, a atividade intelectual se converte em prerrogativa da classe dominante, isto é, dos proprietários de terras, sendo o trabalho manual relegado à condição de uma tarefa própria dos escravos, o que permitiu a Aristóteles entender como próprio do homem o pensar, o contemplar, ou seja, a atividade intelectual, reputando o ato produtivo, o trabalho manual, como uma atividade não digna de homens livres.

Essa mesma relação se mantém na sociedade medieval, dividida entre os senhores feudais (proprietários das glebas) e os servos. Nessa forma social a função intelectual foi reservada à aristocracia e ao clero, com destaque para este último, cabendo o trabalho manual aos servos vinculados às glebas e aos artesãos regidos pelas corporações de ofícios.

O aprofundamento desse processo de divisão em classes ampliou consideravelmente a divisão do trabalho com a conseqüente separação entre trabalho intelectual e trabalho manual conduzindo os membros da sociedade dedicados ao trabalho intelectual ao cultivo de um pensamento abstrato desligado de sua base real, cujas ilusões foram acerbamente criticadas por Marx e Engels na "Ideologia Alemã".

Essa tendência assume novas características com o desenvolvimento do modo de produção capitalista que, sob o lema "conhecimento é poder" enunciado por Francis Bacon, converte a ciência em potência material, acelerando o avanço das forças produtivas por meio da indústria moderna centrada, primeiro, na maquinaria mecânica que, caminhando em direção à automação, desembocará na revolução da informática com suas máquinas eletrônicas que caracterizam o momento atual. Nesse complexo a categoria social dos intelectuais se alarga tanto na quantidade de seus representantes como na ampla gama de modalidades que passam a fazer parte da intelectualidade. Assim, além dos herdeiros das artes liberais da Idade Média, a saber, os artistas, literatos, filósofos, teólogos, médicos e juristas, passam a compor o campo intelectual novos atores como os cientistas de modo geral, desde os físicos e matemáticos até os psicólogos e assistentes 
sociais; os técnicos, dos engenheiros e agrônomos aos gráficos e jornalistas; os administradores, desde os gerentes de empresas e bancos aos dirigentes de organizações não-governamentais; os agentes públicos, desde os funcionários ministeriais aos integrantes das administrações municipais.

\section{Significado estrito do conceito de intelectual}

Entretanto, se o problema da intelectualidade reveste-se de grande amplitude, complexidade e, mesmo, de ambigüidade, já que não falta quem identifique o conceito de intelectual com as classes cultas as mais diversas desde as origens mais remotas "juntando instituições e figuras sociais muito diferentes historicamente, tais como as castas sacerdotais do antigo Egito, os mandarins da China clássica, os sofistas gregos, os clérigos vagantes da Idade Média, os doutos humanistas e, em geral, os estudiosos e artistas de qualquer época e país" (MARLETTI. In: BOBBIO, MATTEUCCI e PASQUINO, 1999, p. 637-638), cumpre distinguir esse sentido lato atribuído ao conceito de intelectual do seu significado mais específico.

Considerando a referida distinção, parece claro que intelectuais, em sentido estrito, é um fenômeno que se tipifica e se desenvolve a partir da época moderna. Conforme esclarece Carlo Marletti (Op. Cit., p. 638), com o desenvolvimento das forças produtivas e da sociedade civil, as artes liberais sofrem profunda transformação sobrevindo a ruptura com o regime das corporações. Sobre essa base material dá-se a reorganização e ampliação do aparelho administrativo e burocrático dos Estados nacionais, flexibiliza-se o acesso aos cargos públicos para além dos privilégios antes detidos pela aristocracia e pelo claro, instituem-se as escolas públicas e modernizam-se as universidades e academias tornando possível a configuração de uma ampla e diversificada camada de intelectuais inimaginável nas condições de existência das "castas, seitas e corporações de doutos e sábios das sociedades antigas e medievais" (idem, ibidem).

Assim, em sua acepção estrita, pode-se considerar que a substantivação do adjetivo latino intellectualis ${ }^{3}$ remonta a meados do século XIX. Ainda conforme Carlo Marletti ( $p$. 637), foi o romancista russo Pietr Dmitrevich Boborykin que cunhou o termo inteligencija, em seguida difundido por Ivan Sergeevich Turgenev e traduzido para as principais línguas européias ${ }^{4}$. Do significado particular referido ao grupo dos intelectuais da Rússia czarista, esse termo "logo se generalizou para designar a classe culta, a categoria das pessoas que têm, em todas as sociedades, uma instrução superior" (idem, ibidem).

\section{O significado político ligado ao conceito de intelectual}

Já ao ser cunhado o termo inteligencsija na Rússia oitocentista, o sentido político se destacava como está realçado na primeira acepção de intelligentsia registrada no Dicionário Houaiss com o adendo "especialmente sua vanguarda política". Mas foi no final do século XIX, com o "Manifesto dos intelectuais" de 14 de janeiro de 1898, a propósito do "Processo Dreyfus", que o significado político do substantivo "intelectuais", por assim dizer, se oficializou. Esse manifesto foi precedido, na véspera, pelo libelo J'accuse publicado por Émile Zola que encabeçou o manifesto também assinado por Anatole France, Marcel Proust, Gabriel Monod, Léon Blum, Lucien Her entre outros. A partir do referido manifesto, ao qual se seguiu uma longa série que continua a se multiplicar, a palavra "intelectual" deixou de indicar apenas uma pessoa em determinada condição social 
ou profissional para abranger, também, o engajamento ou alinhamento numa posição ideológica implicando, com freqüência, a assunção de opções polêmicas.

Essa acepção realça a insatisfação dos intelectuais em relação à situação existente em que a cultura não se reconhece na política e a política, por sua vez, não reconhece as razões da cultura. Entende-se, então, a ligação corrente que se costuma fazer entre os intelectuais e os chamados formadores da opinião pública, pois se atribui aos escritores, artistas, jornalistas, cientistas, de modo geral a todos os que atingiram uma cultura de nível universitário, a condição de intelectuais, entendido esse termo como se referindo àqueles que adquiriram autoridade que lhes permite influenciar os debates públicos. Daí decorre o entendimento da responsabilidade social dos intelectuais e de sua condição de pessoas públicas, o que tem levado certos analistas e militantes políticos a considerar como imprescindível aos intelectuais o exercício não apenas da atividade política em sentido geral, mas também sua filiação a determinado partido político.

\section{Sobre a condição histórico-social dos intelectuais}

Mas a filiação partidária não é uma opção tranquila para os intelectuais, pois estes tendem a se apresentar como categoria social autônoma, supostamente independente ${ }^{5}$ percebendo-se em continuidade histórica como herdeiros de uma longa tradição, como se constituíssem uma classe social distinta das demais. Isso pode ser percebido no verbete antes citado elaborado por Carlo Marletti para o Dicionário de política organizado por Norberto Bobbio, Nicola Matteucci e Gianfranco Pasquini no qual os intelectuais são tratados algumas vezes como "classe culta".

Gramsci, ao iniciar sua investigação sobre a formação dos intelectuais começa exatamente por se perguntar se se trata de "um grupo social autônomo e independente" ou se, ao contrário, "cada grupo social possui sua própria categoria especializada de intelectuais". Sua resposta se encaminha em favor da segunda possibilidade. Admitindo que se trata de um problema complexo em razão "das várias formas que, até nossos dias, assumiu o processo histórico real de formação das diversas categorias de intelectuais", identifica as duas formas mais importantes e as descreve da seguinte maneira:

I) A primeira forma Gramsci denomina de intelectuais orgânicos: "Todo grupo social, nascendo sobre o terreno originário de uma função essencial no mundo da produção econômica, cria junto a si, organicamente, uma ou mais camadas de intelectuais que lhe dão homogeneidade e consciência da própria função não apenas no campo econômico, mas também no campo social e político" (GRAMSCI, 1975 Quaderni [12], vol. II, p. 1513). E exemplifica com o "empreendedor capitalista que cria consigo o técnico da indústria, o cientista da economia política, o organizador de uma nova cultura, de um novo direito, etc. etc." (ibidem). Acrescenta, ainda, que o próprio empreendedor capitalista também revela capacidade dirigente e técnica que, por sua vez, já representa uma função intelectual.

II) A segunda forma denomina-se intelectuais tradicionais. Essa modalidade de intelectuais decorre do fato de que "cada grupo social 'essencial' emergindo na história a partir da estrutura econômica precedente e como expressão do desenvolvimento dessa estrutura, encontrou, ao menos na história até agora transcorrida, categorias sociais preexistentes e que apareciam como representantes de uma continuidade histórica não interrompida mesmo pelas mais complicadas e radicais mudanças das formas sociais e políticas" (idem, p. 1514). A forma mais típica dessa categoria dos intelectuais tradicionais é, segundo Gramsci, a dos eclesiásticos que, no modo de produção feudal, era organicamente ligada à aristocracia fundiária. 
Vê-se, então, que o que define uma categoria de intelectuais como tradicional é o fato de terem pertencido a um modo de produção anterior no qual tinham caráter orgânico. Uma vez superado aquele modo de produção, eles subsistem na nova forma social na condição de tradicionais. Vivendo com "espírito de corpo" sua ininterrupta continuidade histórica e sua qualificação específica, os intelectuais tradicionais se assumem como autônomos e independentes do grupo social dominante.

Assim, se os intelectuais orgânicos gozam de uma autonomia relativa em relação à classe dirigente a que estão vinculados, os intelectuais tradicionais se sentem portadores de uma autonomia por assim dizer absoluta. $\mathrm{Na}$ verdade, a autonomia dos intelectuais orgânicos é relativa porque exercida dentro dos limites necessários para que possam apresentar como universais os interesses particulares da classe que representam à qual, de fato, permanecem organicamente ligados, aliás, como sua própria adjetivação o indica; são eles orgânicos em dois sentidos: porque gerados pelo próprio organismo constitutivo da classe e porque desempenham, perante ela, a função de organizá-la, de conferir-lhe unidade, coerência e homogeneidade; numa palavra, desempenham a função de dar organicidade à classe à qual se encontram umbilicalmente ligados.

Diferentemente, os intelectuais tradicionais não se sentem e de fato não têm ligação orgânica com o grupo essencial dominante. Por isso eles devem ser conquistados, devem ser articulados, de forma subordinada, aos intelectuais orgânicos. Nessa condição, no âmbito da correlação de forças, eles são objeto de disputa entre os intelectuais orgânicos do grupo essencial dominante no interior do bloco histórico instalado e os intelectuais orgânicos do grupo essencial dominado, mas que aspira e luta para se tornar dominante e instalar um novo bloco histórico.

Considerando, por exemplo, o caso brasileiro, lembro-me que na década de 1970 os intelectuais que se aproximavam da população de modo geral e do movimento operário, em particular, eram predominantemente de extração religiosa ligados à igreja progressista e, nessa condição, situavam-se na categoria dos intelectuais tradicionais. Seu empenho em favor dos trabalhadores expressava-se na forma de uma intenção generosa com dificuldade, porém, de se traduzir em ações concretas por falta de uma direção clara que apenas os intelectuais orgânicos poderiam indicar. Seu contato com as massas assumia, mais ou menos, a forma de um apelo do tipo: queremos participar de suas lutas; estamos à disposição; por favor, nos dirijam, indiquem os rumos a seguir e as tarefas a serem desempenhadas. E quando o movimento sindical adquiriu maior consistência e surgiram lideranças que tendiam a assumir organicamente a direção da luta popular, os referidos intelectuais tradicionais se agitaram e viram numa liderança como a do Lula o possível guia que eles buscavam e que desejavam seguir. Penso que é nesse contexto que surgiu o Partido dos Trabalhadores com potencial para galvanizar as lutas populares articulando uma base de apoio centrada em boa parte nos intelectuais tradicionais ligados ou originários da igreja católica.

Em suma, pode-se considerar que os intelectuais orgânicos desempenham quatro funções fundamentais:

a) organizar a função econômica provendo os quadros técnicos, economistas, tecnocratas e similares; b) organizar as concepções heteróclitas dos membros e setores da classe que representam e do conjunto do corpo social numa visão de mundo coerente e homogênea; c) favorecer o consenso espontâneo das grandes massas da população à classe hegemônica na medida em que estabelecem a correspondência entre a referida concepção de mundo coerente e orgânica e a direção que sua classe imprime à vida social; d) assegurar legalmente a disciplina social atuando como funcionários da sociedade política 
(aparelho governamental) nos postos de ministros, juízes, militares, parlamentares etc. (GRISONI e MAGGIORI, 1973, p. 209).

a) No que se refere ao primeiro aspecto, trata-se de atuar na base econômica formando os agentes necessários e organizando a produção.

b) No caso do segundo aspecto a atuação dos intelectuais orgânicos se dá dominantemente no âmbito da sociedade civil elaborando uma concepção de mundo orgânica, coerente e homogênea representativa dos interesses da classe a que estão ligados, ao mesmo tempo em que se empenham em difundir essa concepção para todo o corpo social por meio dos mais diferentes aparelhos ideológicos.

c) Em relação ao terceiro aspecto trata-se de articular no bloco histórico dominante também as massas populares transformando em senso comum difuso sob a forma de uma filosofia de vida a concepção de mundo (ideologia) da classe dominante acolhida sem crítica como se fosse uma forma natural e espontânea de encarar a realidade. Nesse caso, em havendo lideranças que encarnam a posição de intelectuais orgânicos das massas, a estratégia cabível de ação sobre elas por parte dos intelectuais orgânicos da classe dominante é aquela denominada por Gramsci de "transformismo".

Gramsci entende o "transformismo" como um fenômeno geral que se manifesta diferenciadamente em diferentes condições. Refere-se ao transformismo parlamentar, ao transformismo como uma das formas históricas da "revolução passiva" ou "revoluçãorestauração", liga-o, também, ao comentar Croce, à reforma pelo alto, e distingue o "transformismo molecular" do "transformismo de grupos". De um modo geral o "transformismo" (GRAMSCI, 1975, vol.II, p. 962-963) se refere à assimilação dos membros, em especial os intelectuais, das classes subalternas à classe dominante ampliando sua base social. Estudando o período do "Risorgimento" italiano Gramsci detecta dois períodos:

1) De 1860 a 1900 transformismo 'molecular', isto é, as personalidades políticas singulares elaboradas pelos partidos democráticos de oposição se incorporam individualmente à 'classe política' conservadora-moderada (caracterizada pela aversão a toda intervenção das massas populares na vida estatal, a toda reforma orgânica que substituísse uma 'hegemonia' ao cru 'domínio' ditatorial); 2) de 1900 em diante transformismo de inteiros grupos extremistas que passam ao campo moderado (o primeiro acontecimento é a formação do Partido nacionalista com os grupos exsindicalistas e anarquistas, que culmina na guerra da Líbia num primeiro momento e no intervencionismo num segundo momento).

Pelo "transformismo molecular" elementos dos partidos democráticos de oposição, em especial os dirigentes, isto é, seus intelectuais, passam individualmente para o bloco conservador-moderado. Pelo "transformismo de grupos", conjuntos inteiros da elite consciente e ativa das massas aderem ao bloco histórico dominante.

Como interpretar a conjuntura política brasileira atual? Como considerar as mudanças que marcam expressivas lideranças do PT e o próprio Lula? Como entender as metamorfoses que assinalam o PT como um todo? Penso que a categoria do "transformismo" se constitui numa chave teórica preciosa para encontrarmos respostas para essas e outras perguntas. Daí, sua inegável atualidade.Como assinala o próprio Gramsci, a importância do transformismo "não foi, parece, até agora, posta na devida luz como forma de desenvolvimento histórico" (GRAMSCI, 1975, vol. III, p. 1767). Penso, 
pois, que temos aí uma via fecunda a explorar, mesmo porque a constatação de Gramsci de que, na Itália, o movimento operário e socialista "elaborou grupos inteiros de intelectuais que, como grupos, passaram à outra classe", assim como a causa por ele apontada para explicar esse fenômeno, isto é, a "escassa aderência das classes altas ao povo" (Op. Cit., Vol. I, p.396) se aplicam de forma bastante pertinente também ao Brasil.

d) Finalmente, o quarto aspecto diz respeito à atuação dos intelectuais orgânicos no âmbito da sociedade política, isto é, do aparelho estatal provendo quadros de alta qualificação técnica para atuar nos Poderes Executivo, Legislativo e Judiciário, aí incluído o Poder de Polícia ligado ao exercício da coerção considerada legítima.

\section{Intelectuais e memória coletiva}

Constituindo-se como a autoconsciência crítica da classe que representam e empenhando-se em elaborar os interesses da referida classe na forma de uma concepção universal que condense as conquistas da humanidade ao longo da história, os intelectuais concentram a memória coletiva de sua classe no ato mesmo em que se vêem como encarnando a memória do conjunto da humanidade.

Essa questão já foi, de algum modo, contemplada ao longo deste texto na medida em que se buscou caracterizar a categoria dos intelectuais como se situando como herdeira de uma longa tradição, percebendo-se como elo de uma extensa cadeia histórica. Os intelectuais procuram, assim, ancorar sua própria identidade sobre a base da memória histórica, a mais ampla possível.

Esse aspecto é de grande relevância porque a eficácia da ação dos grupos sociais essenciais, isto é, das classes fundamentais que compõem a sociedade em diferentes épocas depende do grau em que dominam, pelo conhecimento, a gênese de si próprias e das condições em que vivem capacitando-se a responder com relativa precisão à questão: por que as coisas são assim e não de outro modo? É pela resposta a essa pergunta que se torna possível a análise concreta da situação identificando os elementos constitutivos da relação de forças como premissa para se inserir ativamente na referida situação impulsionando-a na direção dos objetivos que se busca atingir. Sem a memória dos acontecimentos que nos permitem compreender as coordenadas dos problemas que enfrentamos na atualidade e que queremos resolver, nossas avaliações ficarão limitadas à percepção imediata com poucas chances de compreender seus determinantes mais fundamentais.

Penso ser possível ilustrar a reflexão que estou sugerindo com o seguinte episódio:

Quando se desenrolou no Brasil a polêmica em torno da tramitação do projeto de nossa primeira Lei de Diretrizes e Bases da Educação Nacional no final da década de 1950, eu me encontrava estudando no seminário em Cuiabá. Nessas circunstâncias, a mim não chegou, naquele momento, nenhum eco das acirradas discussões que se travaram nos principais centros culturais do país, em especial em São Paulo e no Rio de Janeiro, com destaque para a memorável convenção em defesa da escola pública realizada na Biblioteca Municipal de São Paulo em 4 de maio de 1960 tendo como presidente de honra Júlio de Mesquita Filho, dono do jornal $O$ Estado de São Paulo sendo que, da defesa da escola particular, fazia parte Alceu Amoroso Lima, o Tristão de Athaíde. De 1964 a 1966, como estudante universitário, participei do movimento estudantil que tinha como uma de suas principais palavras de ordem a luta contra o imperialismo. Os estudantes continuavam defendendo a escola pública e tinham como um dos intelectuais de referência Alceu Amoroso Lima, considerado progressista em contraposição a Júlio de Mesquita Filho, 
taxado de reacionário e lacaio do imperialismo ianque. Em 1968 inicio minha pesquisa de doutorado que teve como tema $O$ conceito de sistema na lei de diretrizes e bases da educação nacional. Fui, então, vasculhar nos arquivos e bibliotecas a trajetória do projeto de LDB e só então me deparei com a constatação de que, na referida Convenção em Defesa da Escola Pública, Júlio de Mesquita Filho pronunciara discurso inflamado em que taxava o movimento católico, que tinha como um de seus principais líderes Alceu Amoroso Lima, de reacionário e ultramontano. E os estudantes estavam ali, engajados na campanha em defesa da escola pública, aclamando entusiasticamente o discurso de Júlio de Mesquita. Apenas cinco anos depois, no âmbito do movimento estudantil, a situação estava invertida: Alceu Amoroso Lima aparecia como progressista e Júlio de Mesquita Filho era o reacionário. Para nós, entretanto, que participávamos do movimento estudantil, era como se toda a história de Júlio de Mesquita Filho, desde o século XIX quando foi fundado o jornal da família, correspondesse ao epíteto que lhe atribuíamos. E, inversamente, toda a história de Alceu Amoroso Lima respaldava a visão lúcida e socialmente avançada que a ele creditávamos. Para mim, os achados da pesquisa histórica tiveram o efeito de uma descoberta da maior relevância aguçando a consciência da importância do conhecimento histórico como condição para a compreensão da própria situação em que nos encontramos. Interpretei a fragilidade das posições assumidas pelo movimento estudantil como conseqüência da falta de memória histórica. E a perda da memória histórica é o que Hobsbawm considera um dos traços mais característicos do período histórico que estamos atravessando, como fica claro no seguinte parágrafo:

\begin{abstract}
"A destruição do passado - ou melhor, dos mecanismos sociais que vinculam nossa experiência pessoal à das gerações passadas - é um dos fenômenos mais característicos e lúgubres do final do século XX. Quase todos os jovens de hoje crescem numa espécie de presente contínuo, sem qualquer relação orgânica com o passado público da época em que vivem. Por isso os historiadores, cujo ofício é lembrar o que outros esquecem, tornam-se mais importantes que nunca no fim do segundo milênio. Por esse mesmo motivo, porém, eles têm de ser mais que simples cronistas, memorialistas e compiladores. Em 1989 todos os governos do mundo, e particularmente todos os ministérios do Exterior do mundo, ter-se-iam beneficiado de um seminário sobre os acordos de paz firmados após as duas guerras mundiais, que a maioria deles aparentemente havia esquecido"(HOBSBAWM, 1994, p.13).
\end{abstract}

\title{
6. Para a criação de intelectuais orgânicos de novo tipo
}

Segundo Gramsci, o ponto de partida para a criação de uma nova categoria de intelectuais é a elaboração crítica da atividade intelectual que já se faz presente em cada um dos membros da classe social fundamental dominada desenvolvendo-a em outra direção. Nesse sentido a formação dos novos intelectuais é parte da tarefa mais ampla acometida à educação de elevação do nível cultural das massas. Essa tarefa implica dois momentos simultâneos e articulados entre si: um momento negativo que consiste na crítica da concepção dominante (a ideologia burguesa); e um momento positivo que significa trabalhar o senso comum buscando extrair o seu núcleo válido (o bom senso) para lhe dar expressão elaborada com vistas à formulação de uma concepção de mundo adequada aos interesses populares. 
Assim, diferentemente da concepção dominante pela qual a relação entre intelectuais e massas é estimulada tendo, porém, como objetivo manter e, até mesmo, ampliar a distância que os separa, a filosofia da práxis postula o estreitamento da relação entre intelectuais e as massas visando elevá-las ao nível dos intelectuais. Gramsci exprime esse movimento enunciando a "passagem do saber ao compreender e ao sentir e, viceversa, do sentir ao compreender e ao saber", da seguinte forma: "o elemento popular 'sente', mas nem sempre compreende ou sabe; o elemento intelectual 'sabe', mas nem sempre compreende e, muito menos, 'sente"” (GRAMSCI, 1978, p. 138-139). E indica a forma de superação dessa contraposição:

Se a relação entre intelectuais e povo-nação, entre dirigentes e dirigidos, entre governantes e governados, se estabelece graças a uma adesão orgânica, na qual o sentimento-paixão torna-se compreensão e, desta forma, saber (não de uma maneira mecânica, mas vivencialmente), só então a relação é de representação, ocorrendo a troca de elementos individuais entre governantes e governados, entre dirigentes e dirigidos, isto é, realiza-se a vida do conjunto, a única que é força social; cria-se o "bloco histórico"” (idem, p. 139).

Mas para chegar a esse novo tipo de intelectual faz-se necessário "submeter-se a um tirocínio psicofísico, o que implica que "se deve convencer a muita gente que também o estudo é um trabalho, e muito cansativo, com um seu especial tirocínio, além de intelectual, também muscular-nervoso: é um processo de adaptação, é um hábito adquirido com esforço, aborrecimento e também com sofrimento (GRAMSCI, 1975, Vol. III, p. 1549).

Em suma, "se se quiser criar uma nova camada de intelectuais, chegando às mais altas especializações, própria de um grupo social que tradicionalmente não desenvolveu as aptidões adequadas, será preciso superar dificuldades inauditas" (GRAMSCI, 1968, p. 139).

Além disso, um intelectual de novo tipo deverá levar em conta a nova forma de sociedade centrada na cidade e na indústria. Isso significa que "o modo de ser do novo intelectual não pode mais consistir na eloqüência". Deve, em lugar disso, consistir "num imiscuir-se ativamente na vida prática, como construtor, organizador, "persuasor permanente", elevando-se da técnica-trabalho "à técnica-ciência e à concepção humanista histórica, sem a qual se permanece 'especialista' e não se chega a 'dirigente' (especialista mais político)" (GRAMSCI, 1968, p. 8).

Foi em sintonia com essas preocupações que propus (SAVIANI, 2010b, p. 387388), no Simpósio de abertura da Conferência Nacional de Educação - CONAE, que se deve considerar com toda a atenção e cuidado o problema do conteúdo da educação. Conforme os documentos legais, a começar pela Constituição Federal e LDB, a educação tem por finalidade o pleno desenvolvimento da pessoa, o preparo para o exercício da cidadania e a qualificação para o trabalho. Levando-se em conta que esses objetivos se referem indistintamente a todos os membros da sociedade brasileira considerados individualmente, podemos interpretar, com Gramsci (1975, vol. III, p. 1547), que o objetivo da educação é conduzir cada indivíduo até a condição de ser capaz de dirigir e controlar quem dirige.

Fica claro que tal objetivo não poderá ser atingido com currículos que pretendam conferir competências para a realização das tarefas de certo modo mecânicas e corriqueiras 
demandadas pela estrutura ocupacional concentrando-se, e ainda de forma limitada, na questão da qualificação profissional e secundarizando o pleno desenvolvimento da pessoa e o preparo para o exercício da cidadania.

Diferentemente dessa tendência dominante, a organização curricular dos vários níveis e modalidades de ensino no âmbito do sistema nacional de educação deverá tomar como referência a forma de organização da sociedade atual, assegurando sua plena compreensão por parte de todos os educandos. Isso significa que se deve promover a abertura da caixa preta da chamada "sociedade do conhecimento". A educação a ser ministrada deverá garantir a todos o acesso aos fundamentos e pressupostos que tornaram possível a revolução micro-eletrônica que está na base dos processos de automação que operam no processo produtivo e das tecnologias da informação que se movem nos ambientes virtuais da comunicação eletrônica.

Assim, além de tornar acessíveis os computadores pela disseminação dos aparelhos e em vez de lançar a educação na esfera dos cursos a distância de forma açodada, é preciso garantir não apenas o domínio técnico-operativo dessas tecnologias, mas a compreensão dos princípios científicos e dos processos que as tornaram possíveis. Se continuarmos pelos caminhos que estamos trilhando, não parece exagerado considerar que estamos, de fato, realizando aquelas profecias dos textos de ficção científica que previram uma humanidade submetida ao jugo de suas próprias criaturas, sendo dirigidas por máquinas engrenadas em processos automáticos. Pois não deixa de ser verdade que, cada vez mais, nos relacionamos com as máquinas eletrônicas, especificamente com os computadores considerando-os fetichisticamente como pessoas a cujos desígnios nós nos sujeitamos e, sem conseguirmos compreendê-los, atribuímos a eles determinadas características psicológicas traduzidas em expressões que os técnicos utilizam para nos explicar seu comportamento, tais como: ele, o computador, não reagiu bem ao seu procedimento; ele é assim mesmo, às vezes aceita o que você propõe e às vezes não aceita; etc.

Nas condições atuais não é mais suficiente alertar contra os perigos da racionalidade técnica advogando-se uma formação centrada numa cultura de base humanística voltada para a filosofia, literatura, artes e ciências humanas à revelia do desenvolvimento das chamadas "ciências duras". É preciso operar um giro da formação na direção de uma cultura de base científica que articule, de forma unificada, num complexo compreensivo, as ciências humano-naturais que estão modificando profundamente as formas de vida passando-as pelo crivo da reflexão filosófica e da expressão artística e literária.

É este o desafio que teremos de enfrentar se quisermos formar uma nova camada de intelectuais organicamente ligados às massas tendo em vista o objetivo de construir um novo bloco histórico cimentado pela hegemonia da concepção de mundo correspondente aos interesses dos trabalhadores. 


\section{Conclusão}

Procurei abordar, de maneira concisa, os elementos que me pareceram mais significativos ligados aos conceitos que compõem o enunciado do tema central desta $\mathrm{X}$ Jornada do HISTEDBR: intelectuais, memória e política tendo como pano de fundo a história da educação. Evidentemente, como conferência de abertura me cabia apenas indicar as linhas básicas sugeridas pelos três conceitos os quais serão objeto de aprofundamento nas Mesas Redondas da Jornada que se debruçarão sobre cada um deles tratando de suas relações com a educação e a história.

O HISTEDBR, como um grupo de estudos e pesquisas, desenvolve obviamente atividade intelectual. E como um grupo que investiga as relações entre história, sociedade e educação articulando grupos de trabalho em diferentes locais distribuídos por todo o país, comporta-se como um intelectual coletivo que, politicamente, está empenhado na pesquisa desinteressada da verdade como via para a construção da memória do povo brasileiro tendo em vista a superação da sociedade atual.

E já que se trata de um intelectual coletivo empenhado na construção e preservação da memória coletiva, convém registrar sua memória lembrando que neste ano o HISTEDBR completa 25 anos de existência. Esta X Jornada está, pois, comemorando um quarto de século de vida do grupo e o faz, de forma pertinente, elegendo como tema central a consideração da história da educação pelo prisma dos conceitos de intelectual, memória e política.

\section{Referências:}

BOBBIO, Norberto; MATTEUCCI, Nicola; PASQUINO, Gianfranco (1999). Dicionário de política, 2 vols., $12^{\mathrm{a}}$ ed. Brasília: Editora UnB.

HOBSBAWM, Eric (1994). Era dos extremos: o breve século XX (1914-1991). São Paulo: Companhia das Letras.

GRAMSCI, Antonio (1968). Os intelectuais e a organização da cultura. Rio de Janeiro: Civilização Brasileira.

GRAMSCI, Antonio (1975). Quaderni del carcere (edizione critica dell'Istituto Gramsci a cura di Valentino Gerratana), 4 vol. Torino: Einaudi.

GRAMSCI, Antonio (1978). Concepção dialética da história, $2^{\mathrm{a}}$ ed. Rio de Janeiro: Civilização Brasileira.

GRISONI, Dominique \& MAGGIORI, Robert (1973). Lire Gramsci. Paris: Éditions Universitaires.

HOUAISS, Antônio; VILLAS, Mauro de Salles; FRANCO, Francisco Manoel de Mello (2001). Dicionário HOUAISS da língua portuguesa. Rio de Janeiro: Objetiva.

MARTINS, Wilson (1976-1978). História da inteligência brasileira, 7 vol. São Paulo, Cultrix/Editora da Universidade de São Paulo (nova edição lançada em 2010 pela Editora da Universidade Estadual de Ponta Grossa).

MARX, Karl (1968). O Capital. Rio de Janeiro: Civilização Brasileira. 
SAVIANI, Dermeval (2010a). História das ideias pedagógicas no Brasil, $3^{\mathrm{a}}$ ed. Campinas: Autores Associados.

SAVIANI, Dermeval (2010b). "Sistema Nacional de Educação articulado ao Plano Nacional de Educação". Revista Brasileira de Educação, v. 15, n. 44, maio/ago. 2010, p. 380-393.

TORRINHA, Francisco (1945). Dicionário latino-português, $3^{\mathrm{a}}$ ed. Porto: Marânus.

Notas:

\footnotetext{
${ }^{1}$ Conferência de abertura da X Jornada do HISTEDBR. Vitória da Conquista, 26 de julho de 2011.

${ }^{2}$ Professor Emérito da UNICAMP, Pesquisador Emérito do CNPq e Coordenador Geral do HISTEDBR

${ }^{3}$ Intellectualis, e significa, em português, intelectual, relativo ao intelecto; e intellectus, us significa percepção, conhecimento; entendimento, inteligência, compreensão; sentido, significação (Ver TORRINHA, 1945, p. 437).

${ }^{4}$ Em português o Dicionário Houaiss (2001, p. 1631) registra as variantes intelligentsia e intelligentzia significando "a classe dos intelectuais na Rússia tsarista no século XIX, especialmente sua vanguarda política"; "a vanguarda intelectual ou artística de qualquer país"; e "o conjunto de intelectuais de um país". É em consonância com essa última acepção que Wilson Martins construiu sua História da inteligência brasileira, uma obra em sete volumes que se estende de 1550 a 1960 (MARTINS, 1976-1978).
}

Recebido: fevereiro-16 $\quad$ Aprovado: março-16 